\title{
Exploring the breastfeeding knowledge level and its influencing factors of pregnant women with gestational diabetes mellitus
}

\author{
Yan Wang ${ }^{1+}$, Hua-xuan You ${ }^{2,3+}$ and Bi-ru Luo ${ }^{3,4^{*}}$ (D)
}

\begin{abstract}
Background: Studies reveal that promoting the breastfeeding knowledge level help to improve breastfeeding behaviors. Promoting breastfeeding knowledge is a simple and economical way to increase breastfeeding rates. However, there are no studies focus on the level of breastfeeding knowledge and factors influencing the knowledge in women with gestational diabetes mellitus (GDM), which is defined as any degree of glucose tolerance impairment first diagnosed during pregnancy. Thus, the objectives of this study were to investigate the breastfeeding knowledge level of GDM pregnant women and explore factors influencing the knowledge level.
\end{abstract}

Methods: Cross-sectional survey and convenience sampling were conducted in this study. The sociodemographic characteristics, caregivers in pregnancy, knowledge source, breastfeeding status and breast status information of participants were collected. Breastfeeding Knowledge Scale was used to assess the breastfeeding knowledge level of pregnant women with GDM. Multiple linear regression was used to analyze the influence factors of breastfeeding knowledge level in this study.

Results: A total of 226 questionnaires were issued and finally 212 valid questionnaires were collected. Some misconceptions still existed (e.g. 'breastfeeding cannot prevent your baby from being overweight' and 'it is advisable to breastfeed 3-4 times per day within 2-3 days after delivery'), although women with GDM had a good score of breastfeeding knowledge (mean score: $103.5 \pm 10.4$ ). Multiple linear regression analysis found that gestational age, family per capita monthly income, educational level, knowledge source were the independent protective factors for breastfeeding knowledge and minority nationality was the independent risk factor. The educational level had the greatest influence on the breastfeeding knowledge level of GDM pregnant women $(\beta=$ $0.210, t=2.978, P=0.003)$.

\footnotetext{
* Correspondence: hxnurs@163.com

${ }^{\dagger}$ Yan Wang and Hua-xuan You contributed equally to this work

${ }^{3}$ Key Laboratory of Birth Defects and Related Diseases of Women and Children (Sichuan University), Ministry of Education, Chengdu 610041, China

${ }^{4}$ Department of Nursing, West China Second University Hospital, Sichuan University, Chengdu 610041, China

Full list of author information is available at the end of the article
} 
(Continued from previous page)

Conclusion: GDM pregnant women with insufficient gestational age, low educational level, low family per capita monthly income and single access to knowledge should be included in the focus of health education on breastfeeding. In-depth and systematic health education should be conducted for pregnant women with GDM to improve their breastfeeding rate.

Keywords: Gestational diabetes mellitus, Breastfeeding, Knowledge

\section{Background}

Breastfeeding is one of the measures proposed by the World Health Organization (WHO) and United Nation Children's Fund (UNICEF) to protect the health of pregnant women and their children [1,2]. Gestational diabetes mellitus (GDM) is defined as any degree of glucose intolerance with onset or first recognition during pregnancy [3]. GDM has adverse effects on the maternal and neonatal outcomes. A large number of studies have confirmed the short-term and long-term benefits of breastfeeding for pregnant women with GDM and their offspring [4]. Breastfeeding can help GDM patients regulate their weight and blood glucose levels and prevent the recurrence of GDM and type 2 diabetes after delivery. For the offspring of women with GDM, breastfeeding can help to reduce the risks of developing obesity and type 2 diabetes in adulthood $[5,6]$. Therefore, breastfeeding is especially recommended and encouraged for women who have GDM.

Women with GDM should insist on breastfeeding. However, studies have shown that GDM women have less willingness to breastfeed and have lower breastfeeding rate than those of normal women at the same stage. Moreover, the breastfeeding rates of GDM women are falling faster [7-10]. Several studies have reported that women with GDM have lower rates of breastfeeding and earlier interruption of breastfeeding in the first 6 months $[11,12]$. Study has shown that the main factors that hinder breastfeeding include maternal factors, social factors and work-related factors [13]. For example, giving birth by cesarean delivery [14], receiving a recommendation from health workers to formula-feed [14], without social support from husband and other relative [15], lack of empathy from female colleagues, uncaring attitudes to breastfeeding, discouragement and criticism from employers and colleagues, difficulty extending maternal leave $[15,16]$ negatively affect breastfeeding. Lack of knowledge is one of the most important barriers of breastfeeding [17]. On the contrary, higher breastfeeding knowledge level is significantly associated with greater breastfeeding intention [18], and stronger breastfeeding confidence [19]. Improving pregnant women's breastfeeding knowledge level can effectively promote the occurrence of breastfeeding behavior and extend actual lactation duration [19-22].
However, current studies have shown that the breastfeeding knowledge level among pregnant women or mothers is not very ideal [23, 24]. Some misconceptions still existed, in spite of considerable awareness of the advantages of breastfeeding [23, 25]. The breastfeeding knowledge level is influenced many factors such as educational level and cultural beliefs [25]. A comprehensive understanding of the factors affecting the breastfeeding knowledge level is conducive to the development of targeted education to improve the knowledge level. However, there are few studies on the breastfeeding knowledge level and it influencing factors in pregnant women with GDM. Therefore, the objectives of this study were to investigate the breastfeeding knowledge level of pregnant women with GDM, and then explore the influencing factors on the knowledge level of breastfeeding.

\section{Methods}

\section{Setting and participants}

We conducted a cross-sectional survey in West China Second University Hospital, Sichuan University, which is a women and children's medical center in West China serving $>5$ provinces. The five provinces, including Sichuan, Guizhou, Yunnan, Qinghai and the Tibet Autonomous Region, lag behind in economic development and maternal and child health care in China. The objectives of this study were to investigate the breastfeeding knowledge level of pregnant women with GDM, and then explore the influencing factors on the knowledge level of breastfeeding. Convenience sampling was used in this study. We selected pregnant women who were waiting to birth from July to October 2017 in the Department of Obstetrics. Pregnant women of 18 years older and had a diagnosis of GDM were included in this survey. Pregnant women were excluded if they: had a history of type 1diabetes or type 2 diabetes; cannot read and write in Chinese; did not sign the informed consent.

Pregnant women with $2 \mathrm{~h} 75$-g Oral Glucose Tolerance Test (OGTT) values exceeding established thresholds (fasting $5.1 \mathrm{mmol} / \mathrm{L}, 1 \mathrm{~h} 10.0 \mathrm{mmol} / \mathrm{L}, 2 \mathrm{~h} 8.5 \mathrm{mmol} /$ L) were diagnosed as GDM. 


\section{Data collection}

We used self-designed questionnaire to collect sociodemographic information such as age, educational level, marital status, the number of childbirths, occupation, family per capita monthly income, nationality, and caregivers in pregnancy, breast status information such as history of breast surgery, breastfeeding status information such as breastfeeding experiences (see Additional file 1).

Breastfeeding Knowledge Scale [26] was used to assess pregnant women's perception of breastfeeding. This scales was developed [27] and by later revised by Zhu, Y. and Wan, H [26].. Breastfeeding Knowledge Scale included 4 parts: benefits of exclusive breastfeeding, breastfeeding skills, breastfeeding storage methods and breastfeeding conditions. This scale was a Chinese 5point Likert scale and with a total of 25 items. Responses range from "Very much agree" to "Very much disagree". Breastfeeding knowledge scores ranged from 25 to 125 , with higher scores indicating the higher breastfeeding knowledge level. Cronbach's a coefficient is 0.820 .

\section{Statistical analysis}

The mean and standard deviation $(M \pm S D)$ were used to describe the quantitative data with normal distribution and approximately normal distribution. T-test and variance analysis were used for univariate analysis. Multiple linear stepwise regression analysis was used for multifactor analysis $(a=0.05)$. Durbin Watson was used to test the independence of the independent variables. Collinearity diagnosis was considered in this study. SPSS23.0 (SPSS Inc., Chicago, IL) was used for statistical analysis.

\section{Results}

\section{Characteristics of participants}

A total of 226 questionnaires were issued and finally 212 valid questionnaires were recovered, with an effective recovery rate of $93.8 \%$. Most pregnant women were between the age of 24 and 44 years old. $65.1 \%$ of participants had a bachelor's degree or above, and $40.1 \%$ of participants had a family's per capita monthly income of 5001-10,000 yuan. A total of 191 (90.1\%) participants came from urban, and 21 (9.9\%) participants came from rural. Husbands and mothers were the main caregivers of participants, accounting for 57.1 and $42.0 \%$, respectively. The main sources of breastfeeding knowledge of pregnant women are family members and friends (55.2\%), followed by medical staff (46.7\%), books (44.8\%), the Internet (44.3\%), newspapers and magazines $(12.3 \%)$ and television $(10.8 \%)$ (Table 1$)$.

\section{Breastfeeding knowledge level of participants}

The average total breastfeeding score of 212 participants was $103.5 \pm 10.4$ points, and the range of respondent scores was 62 points to 125 points. Pregnant women with GDM had a considerable awareness of some breastfeeding knowledge such as 'exclusive breastfeeding is the best option for baby up to 6 months of age', and 'containing antibody composition in breast milk, can enhance baby immunity and reduce disease occurrence'. However, some misconceptions (e.g. 'breastfeeding can prevent the baby being overweight', 'It is advisable to breastfeed 3-4 times per day within 2-3 days after delivery') still existed. The average scores for each item is shown in Table 2.

\section{Univariate analysis of the factors for breastfeeding knowledge level}

There were significant differences in breastfeeding knowledge level among GDM pregnant women with different characteristics. The scores of breast milk storage methods in different age groups were different $(F=$ 3.234, $P=0.023)$. The overall score showed a downward trend with the increase of age. There were statistically significant differences between the groups with different educational level in total score, breastfeeding benefits, breastfeeding skills, breast milk storage methods and breastfeeding conditions $(P<0.05)$. This study revealed that the higher the family per capita monthly income, the higher its breastfeeding knowledge level in total score, breastfeeding benefits, breastfeeding skills, breast milk storage methods and breastfeeding conditions $(P<$ 0.05). This study showed that pregnant women with GDM who have multiple knowledge sources had a higher level of breastfeeding knowledge than those who have single knowledge sources $(P<0.01)$. More detailed information is shown in Table 3.

\section{Multivariate analysis of factors for breastfeeding knowledge level}

Multiple linear stepwise regression analysis was used to exploring the influence factors of breastfeeding knowledge level. This study found that gestational age, educational level, family per capita monthly income and multiple knowledge source were the independent protective factors for breastfeeding knowledge level, and minority nationality was the independent risk factor for breastfeeding knowledge level. The educational level had the greatest influence on the breastfeeding knowledge level of pregnant women with GDM $(\beta=0.210, t=2.978$, $P=0.003)$. The higher the education level of GDM pregnant women, the higher the breastfeeding knowledge level of GDM pregnant women. More detailed information is shown in Table 4.

\section{Discussion}

This study investigated the breastfeeding knowledge level of pregnant women with GDM and explored its 
Table 1 The characteristic of pregnant women

\begin{tabular}{|c|c|c|}
\hline variable & Frequency $(n=212)$ & Percent (\%) \\
\hline \multicolumn{3}{|l|}{ Age (year) } \\
\hline$\leq 29$ & 33 & 15.6 \\
\hline $30-34$ & 85 & 30.1 \\
\hline $35-39$ & 67 & 31.6 \\
\hline$\geq 40$ & 27 & 12.7 \\
\hline \multicolumn{3}{|l|}{ Gestational age (week) } \\
\hline$\leq 36^{+6}$ & 42 & 19.8 \\
\hline$\geq 37$ & 170 & 80.2 \\
\hline Multipara & 111 & 52.2 \\
\hline \multicolumn{3}{|l|}{ Educational level } \\
\hline Junior High and below & 14 & 6.6 \\
\hline Senior High & 15 & 7.1 \\
\hline Junior college & 45 & 21.2 \\
\hline Bachelor or above & 138 & 65.1 \\
\hline \multicolumn{3}{|l|}{ Occupation } \\
\hline Professional & 36 & 17.0 \\
\hline Administrative & 62 & 29.2 \\
\hline Clerk & 55 & 25.9 \\
\hline Farmer & 2 & 0.9 \\
\hline Freelance & 29 & 13.7 \\
\hline Unemployed & 28 & 13.2 \\
\hline \multicolumn{3}{|l|}{ Nationality } \\
\hline Han & 203 & 95.8 \\
\hline Minority & 9 & 4.2 \\
\hline \multicolumn{3}{|l|}{ Marital status } \\
\hline Never married & 0 & 0 \\
\hline Married & 210 & 99.0 \\
\hline Divorced & 2 & 1.0 \\
\hline \multicolumn{3}{|c|}{ Family per capita monthly income (yuan) } \\
\hline$<3000$ & 15 & 7.1 \\
\hline $3001-5000$ & 51 & 24.1 \\
\hline $5001-10,000$ & 91 & 42.9 \\
\hline$>10,000$ & 55 & 25.9 \\
\hline \multicolumn{3}{|l|}{ Caregivers } \\
\hline Pregnant women & 41 & 19.3 \\
\hline Husband & 121 & 57.1 \\
\hline Mother & 89 & 42.0 \\
\hline Mother-in-law & 35 & 16.5 \\
\hline Nanny & 4 & 1.9 \\
\hline Relatives & 7 & 3.3 \\
\hline \multicolumn{3}{|l|}{ Husband's educational level } \\
\hline Junior High and below & 11 & 5.2 \\
\hline Senior High & 12 & 5.7 \\
\hline Junior college & 46 & 21.7 \\
\hline
\end{tabular}

Table 1 The characteristic of pregnant women (Continued)

\begin{tabular}{lll}
\hline variable & Frequency $(\boldsymbol{n}=\mathbf{2 1 2})$ & Percent (\%) \\
\hline Bachelor or above & 143 & 67.5 \\
Knowledge source & 95 & 44.8 \\
Book & 26 & 12.3 \\
Newspaper/magazine & 94 & 44.3 \\
Internet & 23 & 10.8 \\
Television programs & 117 & 55.2 \\
Family member or friends & & \\
Medical staff & & \\
Number of knowledge source & & 41.0 \\
1 & 87 & 59.0 \\
$\geq 2$ & 125 & \\
Breastfeeding experience & & 46.2 \\
Yes & 99 & 53.8 \\
No & 113 & \\
Breastfeeding intention & & 91.5 \\
Yes & 210 & 0.9 \\
No & 2 & 58.5 \\
Health education on breastfeeding & 124 & \\
Yes & 88 & \\
No & & \\
\hline
\end{tabular}

influence factors. The level of breastfeeding knowledge of women with GDM in this study was similar to that of normal pregnant women reported by other researcher [28]. However, some misconceptions of breastfeeding knowledge still existed in GDM population. Multiple linear regression analysis found that gestational age, family per capita monthly income, educational level, knowledge source were the independent protective factors for breastfeeding knowledge level and minority nationality was the independent risk factor for breastfeeding knowledge level. The educational level had the greatest influence on the breastfeeding knowledge level of GDM pregnant women.

This study showed that the $99.1 \%$ of GDM pregnant women had breastfeeding intention before delivery, which was higher than $73.2 \%$ reported by Dai and $92.17 \%$ reported by Zhang $[29,30]$. It revealed that GDM pregnant women had a higher willingness to breastfeed. In Japan, researchers found that $96 \%$ of pregnant women expressed an intention to breastfeed. However, the breastfeeding rate was only $46 \%$ in 4 weeks postpartum. Although there was a strong desire to breastfeed before delivery, pregnant women may stop breastfeeding when they encounter difficulties or obstacles that are difficult to solve in postpartum. Therefore, it suggested that nurses or midwifery should pay more attention to GDM pregnant women who have 
Table 2 The breastfeeding knowledge scores of pregnant women with GDM $(n=212)$

\begin{tabular}{|c|c|}
\hline Items & $\begin{array}{l}\text { Scores }(M \pm S D \text {, } \\
\text { score) }\end{array}$ \\
\hline 1. Exclusive breastfeeding is the best option for baby up to 6 months of age. & $4.85 \pm 0.49$ \\
\hline 2. Containing antibody composition in breast milk, can enhance baby immunity and reduce disease occurrence. & $4.86 \pm 0.47$ \\
\hline 3. Early breastfeeding can prevent constipation of infants. & $4.42 \pm 0.84$ \\
\hline 4. Breastfeeding cannot prevent your baby from being overweight. ${ }^{a}$ & $3.09 \pm 1.25$ \\
\hline 5. Breastfeeding can reduce the incidence of allergic diseases in baby. & $4.45 \pm 0.86$ \\
\hline 6. Breastfeeding is conducive to the development of the baby's intelligence. & $4.49 \pm 0.81$ \\
\hline 7. Breastfeeding is beneficial to uterine contraction, and can reduce postpartum hemorrhage. & $4.64 \pm 0.66$ \\
\hline 8. Breastfeeding cannot help the mother form an intimate relationship with the baby. ${ }^{a}$ & $4.34 \pm 1.32$ \\
\hline 9. Breastfeeding does not necessarily reduce a mother's risk of developing breast cancer in the future. ${ }^{a}$ & $3.96 \pm 1.24$ \\
\hline 10. Breastfeeding does not necessarily reduce a mother's risk of developing ovarian cancer in the future. ${ }^{a}$ & $3.91 \pm 1.18$ \\
\hline 11. Early and frequent sucking can promote milk secretion. & $4.60 \pm 0.75$ \\
\hline 12.The baby should be breast-fed within $2 \mathrm{~h}$ after delivery. & $4.38 \pm 0.90$ \\
\hline 13. It is advisable to breastfeed $3-4$ times per day within $2-3$ days after delivery. ${ }^{a}$ & $3.18 \pm 1.37$ \\
\hline 14.Breast milk can be frozen for 3 months after extrusion. & $3.52 \pm 1.12$ \\
\hline 15. Breast milk can keep fresh for $24-48 \mathrm{~h}$ in cold storage after extrusion. & $3.56 \pm 1.14$ \\
\hline 16. The breast milk can be microwaved before feeding the baby. ${ }^{a}$ & $4.00 \pm 1.14$ \\
\hline 17. Breastfeeding should be given according to the actual needs of the newborn. & $4.45 \pm 0.80$ \\
\hline $\begin{array}{l}\text { 18. Although complementary foods are added after } 4-6 \text { months of age, breastfeeding can be maintained until the baby is } 1- \\
2 \text { years old. }\end{array}$ & $4.32 \pm 0.89$ \\
\hline 19. Breast size affects milk production. ${ }^{a}$ & $4.19 \pm 0.97$ \\
\hline 20. Mothers with sunken nipples must not breastfeed. ${ }^{a}$ & $4.30 \pm 0.88$ \\
\hline 21. Mothers with cracked nipples must not breastfeed. ${ }^{a}$ & $4.09 \pm 1.02$ \\
\hline 22. After breastfeeding, the remaining milk should not be excreted. ${ }^{a}$ & $4.06 \pm 1.14$ \\
\hline 23. Water should be given to the baby after breastfeeding every time. ${ }^{a}$ & $3.96 \pm 1.21$ \\
\hline 24. Only $5-10 \mathrm{ml} /$ time should be fed to the baby on the first day after birth. ${ }^{a}$ & $3.49 \pm 1.10$ \\
\hline 25. Breastfeeding helps mothers regain their pre-pregnancy weight as quickly as possible. & $4.40 \pm 0.90$ \\
\hline Total score & $103.5 \pm 10.4$ \\
\hline
\end{tabular}

Note: GDM Gestational diabetes mellitus; Breastfeeding benefits include item 2,3,4,5,6,7,8,9,10,25; Breastfeeding skills include item 1,11,12,13,17,22,23; Breast milk storage methods include 14,15,16; Breastfeeding conditions include item 18,19,20,21,24. ${ }^{a}$ Item 4, 8, 9, 10, 13, 16, 19, 20, 21, 22, 23 , 24 were scored in reverse

breastfeeding intention and strengthen their intention by health education or peer education. Additionally, nurses or midwifery should focus on postnatal breastfeeding status of GDM women and assisted them to solve the difficulties to breastfeeding in a timely manner. Moreover, to form correct breastfeeding cognition and improve breastfeeding rate of women with GDM, scientific and systematic health education should be carried on these population.

This study showed that pregnant women with GDM had an average level of breastfeeding knowledge. However, some misconceptions of breastfeeding knowledge still existed in GDM population. Pregnant women with different sociodemographic characteristics had different understanding degree of breastfeeding knowledge. GDM pregnant women who did not receive health education of breastfeeding had insufficient understanding of breastfeeding conditions, such as 'breast size affecting milk secretion'. However, GDM pregnant women who received health education on breastfeeding had significantly higher knowledge level, which was consistent with the conclusion of Thomas's report [31]. GDM pregnant women who had lower educational level, premature birth, and lower family per capita income, and whose husband had lower educational level were not optimistic about the mastery of breastfeeding knowledge about breastfeeding conditions and breastfeeding benefits, which was supported by some researchers' reports [20, 23, 32]. Research revealed that the higher the knowledge level of breastfeeding, the less likely it is to terminate breastfeeding early [33]. Breastfeeding knowledge education can help avoid the occurrence of early interruption of breastfeeding, suggesting that breastfeeding knowledge education was necessary for GDM pregnant women. 
Table 3 Subgroup analysis of breastfeeding knowledge level of pregnant women $(M \pm S D$, score)

\begin{tabular}{|c|c|c|c|c|c|}
\hline Subgroup & Breastfeeding benefits & Breastfeeding skills & Breast milk storage methods & Breastfeeding conditions & Total score \\
\hline \multicolumn{6}{|l|}{ Age (year) } \\
\hline$\leq 29$ & $42.3 \pm 6.3$ & $30.0 \pm 3.9$ & $11.5 \pm 2.2$ & $20.2 \pm 3.4$ & $104.0 \pm 13.4$ \\
\hline $30-34$ & $41.8 \pm 6.5$ & $29.5 \pm 4.7$ & $11.2 \pm 2.3$ & $20.6 \pm 3.9$ & $104.5 \pm 9.9$ \\
\hline $35-39$ & $42.4 \pm 5.0$ & $28.5 \pm 3.3$ & $10.9 \pm 2.1$ & $19.6 \pm 2.9$ & $101.4 \pm 10.2$ \\
\hline$\geq 40$ & $43.8 \pm 5.1$ & $29.9 \pm 3.3$ & $9.9 \pm 1.6$ & $21.1 \pm 2.6$ & $104.7 \pm 8.1$ \\
\hline$F$ & 0.740 & 1.500 & 3.234 & 1.838 & 1.361 \\
\hline$P$ value & 0.529 & 0.216 & 0.023 & 0.141 & 0.256 \\
\hline \multicolumn{6}{|l|}{ Educational level } \\
\hline Junior High and below & $37.6 \pm 4.4$ & $27.1 \pm 3.8$ & $10.0 \pm 1.6$ & $17.9 \pm 2.8$ & $92.6 \pm 11.1$ \\
\hline Senior High & $38.5 \pm 11.4$ & $25.8 \pm 8.8$ & $10.1 \pm 3.0$ & $18.0 \pm 5.8$ & $98.9 \pm 9.7$ \\
\hline Junior college & $41.9 \pm 5.8$ & $28.9 \pm 3.6$ & $10.7 \pm 2.3$ & $19.8 \pm 3.1$ & $101.3 \pm 12.1$ \\
\hline Bachelor or above & $43.4 \pm 4.6$ & $30.1 \pm 3.2$ & $11.3 \pm 2.0$ & $21.0 \pm 2.9$ & $105.8 \pm 8.8$ \\
\hline F & 7.463 & 7.825 & 3.394 & 7.528 & 10.075 \\
\hline$P$ value & $<0.001$ & $<0.001$ & 0.019 & $<0.001$ & $<0.001$ \\
\hline \multicolumn{6}{|l|}{ Nationality } \\
\hline Han & $42.5 \pm 5.8$ & $29.4 \pm 4.0$ & $11.0 \pm 22.2$ & $20.4 \pm 3.3$ & $103.9 \pm 10$ \\
\hline Minority & $39.7 \pm 5.2$ & $26.9 \pm 4.3$ & $10.6 \pm 1.7$ & $17.6 \pm 3.9$ & $94.7 \pm 12.3$ \\
\hline$t$ & 1.417 & 1.877 & 0.665 & 2.529 & 2.640 \\
\hline$P$ value & 0.158 & 0.062 & 0.507 & 0.012 & 0.009 \\
\hline \multicolumn{6}{|c|}{ Family per capita monthly income (yuan) } \\
\hline$<3000$ & $39.5 \pm 6.4$ & $27.4 \pm 4.4$ & $10.3 \pm 2.2$ & $18.6 \pm 3.2$ & $95.8 \pm 14.3$ \\
\hline $3001-5000$ & $41.0 \pm 7.8$ & $28.3 \pm 5.5$ & $10.6 \pm 2.2$ & $19.5 \pm 4.0$ & $101.3 \pm 10.7$ \\
\hline $5001-10,000$ & $42.3 \pm 4.6$ & $29.8 \pm 3.3$ & $11.2 \pm 2.0$ & $20.3 \pm 3.1$ & $103.5 \pm 9.8$ \\
\hline$>10,000$ & $44.3 \pm 4.6$ & $30.1 \pm 3.1$ & $11.8 \pm 2.2$ & $21.6 \pm 2.8$ & $107.8 \pm 8.0$ \\
\hline$F$ & 4.298 & 3.312 & 3.870 & 5.393 & 7.103 \\
\hline$P$ value & 0.006 & 0.021 & 0.010 & 0.001 & $<0.001$ \\
\hline \multicolumn{6}{|l|}{ Husband's education level } \\
\hline Junior High and below & $36.5 \pm 13.1$ & $25.7 \pm 9.2$ & $9.1 \pm 3.3$ & $16.4 \pm 5.9$ & $96.4 \pm 11.6$ \\
\hline Senior High & $41.8 \pm 5.5$ & $30.3 \pm 3.7$ & $11.1 \pm 1.9$ & $19.9 \pm 2.9$ & $103.2 \pm 11.4$ \\
\hline Junior college & $42.0 \pm 5.5$ & $28.8 \pm 4.1$ & $10.9 \pm 2.1$ & $19.9 \pm 2.8$ & $101.6 \pm 12.2$ \\
\hline Bachelor or above & $43.1 \pm 4.7$ & $29.3 \pm 3.3$ & $11.2 \pm 2.2$ & $20.8 \pm 3.4$ & $104.7 \pm 9.5$ \\
\hline$F$ & 4.612 & 4.029 & 3.350 & 6.640 & 2.683 \\
\hline$P$ value & 0.014 & 0.008 & 0.020 & $<0.001$ & 0.048 \\
\hline \multicolumn{6}{|l|}{ Gestational age (week) } \\
\hline$\leq 36^{+6}$ & $40.3 \pm 5.6$ & $28.4 \pm 4.1$ & $10.5 \pm 2.0$ & $19.3 \pm 3.0$ & $98.5 \pm 12.0$ \\
\hline$\geq 37$ & $42.8 \pm 5.8$ & $29.6 \pm 4.0$ & $11.2 \pm 2.2$ & $20.5 \pm 3.5$ & $104.8 \pm 9.7$ \\
\hline$t$ & -2.571 & -1.732 & -1.765 & -2.201 & -3.598 \\
\hline$P$ value & 0.011 & 0.085 & 0.079 & 0.029 & $<0.001$ \\
\hline \multicolumn{6}{|c|}{ Breastfeeding health education } \\
\hline Yes & $43.0 \pm 6.4$ & $29.8 \pm 4.3$ & $11.3 \pm 2.4$ & $20.7 \pm 3.4$ & $105.7 \pm 9.8$ \\
\hline No & $41.4 \pm 5.0$ & $28.7 \pm 3.7$ & $10.8 \pm 1.9$ & $19.8 \pm 3.5$ & $100.7 \pm 10.7$ \\
\hline$t$ & -2.100 & -1.524 & -1.574 & -1.853 & -3.335 \\
\hline$P$ value & 0.037 & 0.129 & 0.117 & 0.065 & 0.001 \\
\hline
\end{tabular}

Number of knowledge source 
Table 3 Subgroup analysis of breastfeeding knowledge level of pregnant women $(M \pm S D$, score) (Continued)

\begin{tabular}{clllll}
\hline Subgroup & Breastfeeding benefits & Breastfeeding skills & Breast milk storage methods & Breastfeeding conditions & Total score \\
\hline 1 & $40.7 \pm 7.0$ & $28.4 \pm 4.8$ & $10.5 \pm 2.3$ & $19.3 \pm 3.8$ & $100.0 \pm 11.5$ \\
$\geq 2$ & $43.5 \pm 4.5$ & $30.0 \pm 3.3$ & $11.4 \pm 2.0$ & $21.0 \pm 2.9$ & $105.9 \pm 8.9$ \\
$t$ & -3.562 & -2.803 & -3.243 & -3.768 & -4.206 \\
$P$ value & $<0.001$ & 0.006 & 0.001 & $<0.001$ & $<0.001$ \\
\hline
\end{tabular}

Multivariate regression analysis revealed that gestational age, education level, family per capita monthly income, and knowledge source were independent protective factor for breastfeeding knowledge level. This result was similar to Thomas' study [31]. The study found that breastfeeding counseling, socioeconomic status and educational level had a great impact on breastfeeding cognition of primipara. However, Thomas's study did not report the impact of gestational age and knowledge source on breastfeeding cognitions. This study showed that the education level had the greatest influence on the knowledge of breastfeeding. Therefore, in nursing work, pregnant women with lower educational level cannot be ignored. These population had weaker ability to understand and grasp the knowledge. Therefore, there was a need for detailed and in-depth health education on breastfeeding for low-educational-level pregnant women. There was a growing concern among pregnant women about the breastfeeding knowledge with the increasing of gestational age. Study showed that $66.3 \%$ of pregnant women were willing to receive knowledge education in the second trimester [20], which was the time for pregnant women to have regular prenatal examination. Therefore, medical staff should make full use of this period to educate pregnant women about breastfeeding. Moreover, studies found that the medical staff is the main source of breastfeeding knowledge of women and is also the main object for help of any difficulty of women. In some countries and regions, pregnant women get knowledge mainly by means of the media and women's magazines [20,33]. Therefore, GDM pregnant women should be provided health education on breastfeeding through a variety of ways, which is conducive to improving the knowledge level of breastfeeding. More diversified forms of health education should be carried out, such as breastfeeding salons and WeChat network platforms, and Internet media resources should be fully utilized to carry out health education.

This study had three limitation. First, only one hospital was included in this study, which is the one of the best hospitals of west China. Our participants almost were well educated and had high household income. So, this may reduce the representativeness of the sample in this study. Second, Multiple linear regression analysis showed that the influencing factors studied in this study could only explain $20.7 \%$ of the variation in breastfeeding knowledge score, revealing that there were other factors that did not be found and need to be studied. Thirdly, the validation and pilot-testing of self-designed questionnaire were not conducted.

\section{Conclusion}

A cross-sectional survey was conducted in West China. This study showed that GDM pregnant women had a strong willingness to breastfeed before delivery, and an average level of breastfeeding knowledge. However, some misconceptions of breastfeeding knowledge still existed in these GDM population. Pregnant women with GDM and gestational age less than 37 weeks of gestation, low educational level, low family per capita monthly income and single access to knowledge should be the focus of health education on breastfeeding. Therefore, special attention should be paid to these population. Systematic and in-depth breastfeeding health education should be carried on these women. Medical staff were still

Table 4 Multiple linear regression analysis of breastfeeding knowledge level

\begin{tabular}{|c|c|c|c|c|}
\hline Variables & $\beta$ & Standardized $\beta$ & $t$ & $P$ \\
\hline Constant & 85.465 & - & 15.297 & 0.000 \\
\hline Gestational age $\left(1=\right.$ gestational age $<36^{+6}$ week $)$ & 3.970 & 0.151 & 2.389 & 0.018 \\
\hline Nationality $(1=$ Han $)$ & -7.942 & -0.155 & -2.478 & 0.014 \\
\hline Educational level ( 1 = Junior High and below) & 2.471 & 0.210 & 2.978 & 0.003 \\
\hline Family per capita monthly income ( $1=$ income $<3000$ yuan $)$ & 1.784 & 0.151 & 2.196 & 0.029 \\
\hline Knowledge source ( $1=1$ source) & 1.407 & 0.172 & 2.661 & 0.008 \\
\hline
\end{tabular}

Note: $R^{2}=0.226$; Adjust $R^{2}=0.207 ; F=4.948, P=0.027$. The value of Durbin Watson was 2.043, suggesting the independence of these variables. Tolerance in the model were as follows: gestational age 0.947 , educational level 0.764 , family per capita monthly income 0.808 , and knowledge sources 0.908 , nationality 0.976 . "-" no value 
the main source of breastfeeding knowledge for pregnant women. Thus, medical staff especially nurse and midwifery should play a major role in breastfeeding health education. At the same time, more diversified forms of health education, such as breastfeeding salons, WeChat network platforms, and Internet media resources should be fully utilized to carry out health education for pregnant women with GDM.

\section{Supplementary Information}

The online version contains supplementary material available at https://doi. org/10.1186/s12884-020-03430-9.

Additional file 1. Questionnaire on breastfeeding knowledge and its influence factors of pregnant women with gestational diabetes mellitus.

\section{Abbreviations}

GDM: Gestational diabetes mellitus; WHO: World Health Organization; UNICEF: United Nation Children's Fund; M \pm SD: Mean \pm Standard Deviation; OGTT: Oral glucose tolerance test

\section{Acknowledgements}

Not applicable.

\section{Authors' contributions}

$\mathrm{BL}$ contributed to study design and manuscript revision. YW and HY contributed to collect, analyze and interpret data and write this manuscript All authors have read and approved the manuscript.

\section{Funding}

Not applicable.

\section{Availability of data and materials}

The datasets used and/or analyzed during the current study are available from the corresponding author on reasonable request.

\section{Ethics approval and consent to participate}

The protocol for this investigation was approved by the Ethics Committee of the West China Second University Hospital, Sichuan University. The research assistants obtained the written informed consent from study participants at the beginning of this study.

\section{Consent for publication}

Not applicable.

\section{Competing interests}

The authors declare that they have no competing interests.

\section{Author details \\ 'Key Laboratory of Birth Defects and Related Diseases of Women and Children (Sichuan University), Ministry of Education, West China Second University Hospital Mest China School of Nursing, Sichuan University, Chengdu 610041, China. ${ }^{2}$ Department of Reproductive Endocrinology Nursing, West China Second University Hospital, Sichuan University/West China School of Nursing, Sichuan University, Chengdu 610041, China. ${ }^{3}$ Key Laboratory of Birth Defects and Related Diseases of Women and Children (Sichuan University), Ministry of Education, Chengdu 610041, China. ${ }^{4}$ Department of Nursing, West China Second University Hospital, Sichuan University, Chengdu 610041, China.}

Received: 6 September 2020 Accepted: 16 November 2020

Published online: 23 November 2020

\section{References}

1. United Nation Children's Fund. Neonatal mortality; 2017. https://data.unicef. org/topic/child-survival/ neonatal-mortality/. Accessed 4 Nov. 2020.
2. World Health Organization. Exclusive breastfeeding for six months best for babies everywhere; 2011. http://www.who.int/mediacentre/news/ statements/2011/breastfeeding_20110115/en/. Accessed 4 Nov. 2020.

3. Chiefari $E$, Arcidiacono B, Foti D, Brunetti A. Gestational diabetes mellitus: an updated overview. J Endocrinol Investig. 2017;40(9):899.

4. Gunderson EP. The role of lactation in GDM women. Clin Obstet Gynecol. 2013;56(4):844-52.

5. Much D, Beyerlein A, Rossbauer M, Hummel S, Ziegler AG. Beneficial effects of breastfeeding in women with gestational diabetes mellitus. Mol Metab. 2014;3(3):284-92.

6. Choi MJ, Chung CW. Patterns of diagnosis and risk factors for type 2 diabetes in women with a history of gestational diabetes mellitus. Perspect Nurs Ence. 2016;13(1):17.

7. Guo H, Wang J, Xu Q. Research progress of postpartum breastfeeding in patients with gestational diabetes mellitus. J Nurs Sci. 2015;30(24):99-102.

8. Haile ZT, Oza-Frank R, Azulay Chertok IR, Passen N. Association between history of gestational diabetes and exclusive breastfeeding at hospital discharge. J Hum Lact. 2015;32(3):NP36-43.

9. Oza-Frank R, Chertok I, Bartley A. Differences in breast-feeding initiation and continuation by maternal diabetes status. Public Health Nutr. 2015;18(04):727-35.

10. Cordero L, Thung S, Landon MB, Nankervis CA. Breast-feeding initiation in women with Pregestational diabetes mellitus. Clin Pediatr. 2014;53(1):18-25.

11. Baerug A, Sletner L, Laake P, Fretheim A, LoLand BF, Waage CW, et al. Recent gestational diabetes was associated with mothers stopping predominant breastfeeding earlier in a multi-ethnic population. Acta Paediatr. 2018;107(6):1028-35.

12. Chamberlain CR, Wilson AN, Amir LH, O'Dea K, Campbell S, Leonard D, et al. Low rates of predominant breastfeeding in hospital after gestational diabetes, particularly among indigenous women in Australia. Aust N Z J Public Health. 2017:41(2):144-50.

13. Gebrekidan K, Fooladi E, Plummer V, Hall H. Enablers and barriers of exclusive breastfeeding among employed women in low and lower middle-income countries. Sex Reprod Healthc. 2020;25:100514.

14. Dun-Dery EJ, Laar AK. Exclusive breastfeeding among city-dwelling professional working mothers in Ghana. Int Breastfeed J. 2016;11:23.

15. Omer-Salim A, Suri S, Dadhich JP, Faridi MMA, Olsson P. 'Negotiating the tensions of having to attach and detach concurrently': a qualitative study on combining breastfeeding and employment in public education and health sectors in New Delhi, India. Midwifery. 2015;31(4):473-81.

16. Riaz $\mathrm{S}$, Condon $\mathrm{L}$. The experiences of breastfeeding mothers returning to work as hospital nurses in Pakistan: a qualitative study. Women Birth. 2019; 32(2):E252-E8.

17. Zhou X, Zhang H. Application of "problem based learning" in prenatal education on breastfeeding. Chin J Nurs. 2006:07:624-6.

18. Hamade H, Naja F, Keyrouz S, Hwalla N, Karam J, Al-Rustom L, et al. Breastfeeding knowledge, attitude, perceived behavior, and intention among female undergraduate university students in the Middle East: the case of Lebanon and Syria. Food Nutr Bull. 2014;35(2):179-90.

19. Chezem J, Friesen C, Boettcher J. Breastfeeding knowledge, breastfeeding confidence, and infant feeding plans: effects on actual feeding practices. Jognn-J Obstet Gynecol Neonatal Nurs. 2003;32(1):40-7.

20. Zhao $Y$, Sun $M$. The investigation of pregnant women' cognition about breast feeding Chinese medical record. 2012;13(07):72-4

21. Zhu $Y$, Wan $H$. Influencing factors of purebreastfeeding behavior at postpartum 4 months on the basis on planned behavior theory. Chin Nurs Res. 2016;30(8C):3051-3.

22. Little EE, Alejandra Polanco M, Baldizon SR, Wagner P, Shakya H. Breastfeeding knowledge and health behavior among Mayan women in rural Guatemala. Soc Sci Med. 2019;242:112565.

23. Shi H, Wang J. Investigation on the cognitive status of breastfeeding knowledge of pregnant women and countermeasures. Chin J Prim Med Pharm. 2015;22(23):3659-6061.

24. Dukuzumuremyi JPC, Acheampong K, Abesig J, Luo J. Knowledge, attitude, and practice of exclusive breastfeeding among mothers in East Africa: a systematic review. Int Breastfeed J. 2020;15:1.

25. Zhou Q, Younger KM, Kearney JM. An exploration of the knowledge and attitudes towards breastfeeding among a sample of Chinese mothers in Ireland. BMC Public Health. 2010;3(10):722.

26. Zhu $Y$, Wan $\mathrm{H}$. Influencing factors of pure breastfeeding behavior at postpartum 4 months on the basis on planned behavior theory. Chin Nurs Res. 2016;30(24):3051-3. 
27. Wan H, Hu S, Thobaben M, Hou Y, Yin T. Continuous primary nursing care increases satisfaction with nursing care and reduces postpartum problems for hospitalized pregnant women. Contemp Nurse. 2011;37(2):149-59.

28. Huang P, Yao J, Liu X, Luo B. Individualized intervention to improve rates of exclusive breastfeeding a randomised controlled trial. Medicine. 2019;98:47.

29. Dai H, Hu H. Clinical analysis of breastfeeding in pregnant women with gestational diabetes mellitus. Matern Child Health Care China. 2012;27(07): 1001-3.

30. Zhang S. Study on breastfeeding status and influencing factors of pregnant women with diabetes mellitus at different postpartum stages. Matern Child Health Care China. 2015;30(33):5765-7.

31. Thomas JS, Yu EA, Tirmizi N, Owais A, Das SK, Rahman S, et al. Maternal knowledge, attitudes and self-efficacy in relation to intention to exclusively breastfeed among pregnant women in rural Bangladesh. Matern Child Health J. 2015:19(1):49-57.

32. Meedya S, Fahy K, Kable A. Factors that positively influence breastfeeding duration to 6 months: a literature review. Women Birth. 2010;23(4):135-45.

33. Trojanowska A, Brodowicz-Krol M, Trojanowska P. Knowledge of young women concerning the impact of natural feeding on the growth and state of health of a baby. Ann Agric Environ Med. 2017;24(3):484-8.

\section{Publisher's Note}

Springer Nature remains neutral with regard to jurisdictional claims in published maps and institutional affiliations.

Ready to submit your research? Choose BMC and benefit from:

- fast, convenient online submission

- thorough peer review by experienced researchers in your field

- rapid publication on acceptance

- support for research data, including large and complex data types

- gold Open Access which fosters wider collaboration and increased citations

- maximum visibility for your research: over $100 \mathrm{M}$ website views per year

At BMC, research is always in progress.

Learn more biomedcentral.com/submissions 